\title{
Assessment of Dental Sexual Dimorphism in Children Using Odontometry: A Descriptive Study
}

\author{
NB Nagaveni ${ }^{1}$, Safina Masroor ${ }^{2}$, Poornima Parameswarappa $^{3}$
}

\begin{abstract}
Aim and objective: To measure the mandibular canine dimension, intercanine distance, and calculate the mandibular canine index (MCI) to assess their usefulness in gender determination.

Materials and methods: The study was performed on 60 boys and 60 girls. Impressions of both the arches were made using alginate material, poured in dental stone, and was allowed to set and then the cast bases were made with dental plaster. A digital Vernier caliper was used for obtaining the measurements. The intermolar arch width, intercanine width, and $\mathrm{MCl}$ were calculated. Sexual dimorphism was calculated using the formula given by Garn and Lewis. The data were statistically analyzed using the unpaired " $t$ " test.

Results: There was no statistical significance seen in the mandibular intermolar and intercanine distance between the two groups. The MCI between males and females showed a statistically significant difference.

Conclusion: Intermolar distance, intercanine distance, and $\mathrm{MCl}$ can be used as an alternative tool for sex determination as an inexpensive and alternative method.

Clinical significance: The first study in itself to determine gender in the pediatric population in the city of Davangere, India.

Keywords: Canine, Davangere, Dental model, Forensic odontology, Primary molars.

CODS Journal of Dentistry (2020): 10.5005/jp-journals-10063-0062
\end{abstract}

\section{INTRODUCTION}

Forensic dentistry plays a significant role in the identification of man-made or natural disasters and many other events that result in multiple fatalities that may not be identifiable through conventional methods such as fingerprints. ${ }^{1}$

The theory behind forensic dentistry is "no two mouths are alike". Forensic dentistry or forensic odontology involves dentists' participation in assisting legal and criminal issues and in the identification of humans. It refers to the proper handling, examination, and evaluation of dental evidence, which will be then presented in the interest of justice. $^{2}$

Sex determination becomes the first priority by a forensic investigator in the process of identification of bodies mutilated beyond recognition due to major mass disasters such as in the case of mishaps, chemical and nuclear bomb explosions, natural disasters, crime investigations, and ethnic studies. Determination of sex using skeletal remains presents a great problem to forensic experts, especially when only fragments of the body are recovered. Forensic dentists can assist other experts to determine the sex of the remains using teeth and skull. ${ }^{3}$

Teeth are good material in living and non-living populations for anthropological, genetic, odontologic, and forensic investigations. This is due to the hardness and high resistance of dental tissues to degradation and putrefaction which enable the teeth to survive for longer periods than other human tissues. ${ }^{4}$

"Sexual dimorphism" refers to those differences in size, stature, and appearance between males and females that can be applied to dental identification because no two mouths are alike. ${ }^{5}$ Recently, there has been an increased interest in using molars as an aid in gender determination. Therefore, the present study was carried out, with the objectives to measure the intermolar distance to assess its usefulness in gender determination.
${ }^{1}$ Department of Pediatric and Preventive Dentistry, Hitkarinia Dental College and Hospital, Jabalpur, Madhya Pradesh, India

2,3 Department of Pediatric and Preventive Dentistry, College of Dental Sciences, Davangere, Karnataka, India

Corresponding Author: Safina Masroor, Department of Pediatric and Preventive Dentistry, College of Dental Sciences, Davangere, Karnataka, India, Phone: +919066611725, e-mail: safinamasroor13@ gmail.com

How to cite this article: Nagaveni NB, Masroor S, Parameswarappa P. Assessment of Dental Sexual Dimorphism in Children Using Odontometry: A Descriptive Study. CODS J Dent 2020;12(2):26-30.

Source of support: Nil

Conflict of interest: None

\section{Materials and Methods}

A total of 120 children, comprising 60 boys and 60 girls aged between 5 years and 10 years irrespective of race and socioeconomic status were randomly selected from the outpatient clinic of the Department of Pediatric and Preventive Dentistry at College of Dental Sciences, Davangere, Karnataka, India.

\section{Inclusion Criteria (Fig. 1)}

- Clinically healthy periodontium.

- Caries-free teeth.

- Subjects with normal overjet and overbite.

\section{Exclusion Criteria}

- Developmental abnormalities of teeth.

- Physical or chemical injuries to the teeth.

- Teeth with proximal restoration/crowns. 


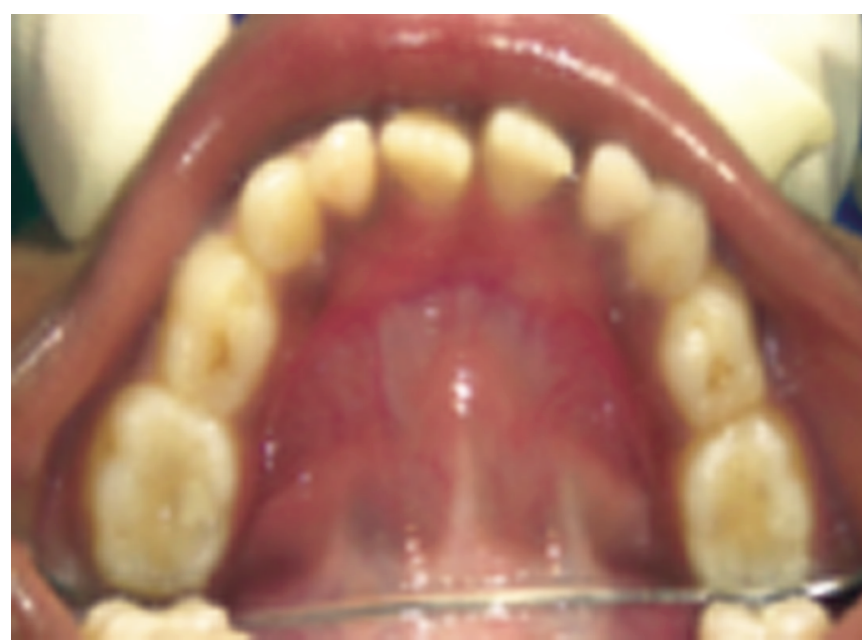

Fig. 1: Examination of the subject

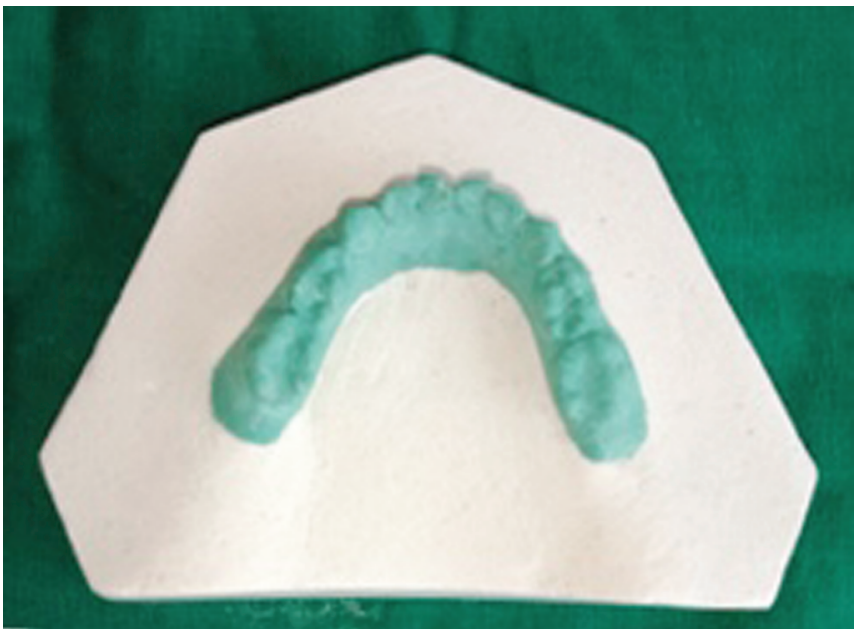

Fig. 3: Cast and base of mandibular arch

- Subjects with deleterious oral habits such as bruxism and tongue thrusting.

Impressions of mandibular arches were made using alginate impression material (Fig. 2). The impressions were disinfected with $0.5 \%$ sodium hypochlorite. The impressions were poured in dental stone and were allowed to set and then the cast bases were made with dental plaster (Fig. 3). A digital Vernier caliper calibrated to an accuracy of $\pm 0.02 \mathrm{~mm}$ was used for obtaining the measurements.

Mandibular study models were used for the analysis. The intermolar arch width was calculated from the central fossa of a deciduous second molar on either side using a digital Vernier caliper (Fig. 4). The mandibular canine width was measured using a digital Vernier caliper and is defined as the greatest mesiodistal (MD) dimension of the mandibular canine on either side of the jaw, and an average of this was taken. The intercanine width was measured as the linear distance between the cusp tips of the right and left mandibular canine (Fig. 5). The observed mandibular canine index $(\mathrm{MCl})$ was calculated using the formula:

$\mathrm{MCl}=$ Mesiodistal crown width of mandibular canine / intercanine width

Sexual dimorphism was calculated using the formula given by Garn and Lewis ${ }^{6}$

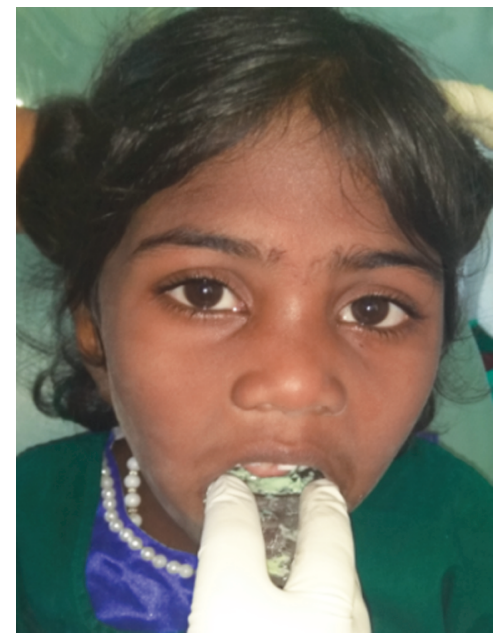

Fig. 2: Impression making of the mandibular arch

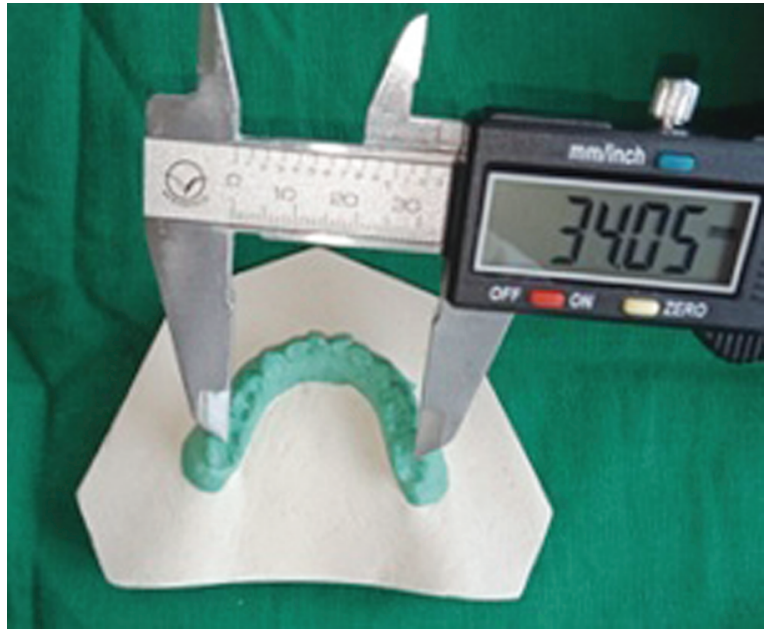

Fig. 4: Measurement of mandibular intermolar distance

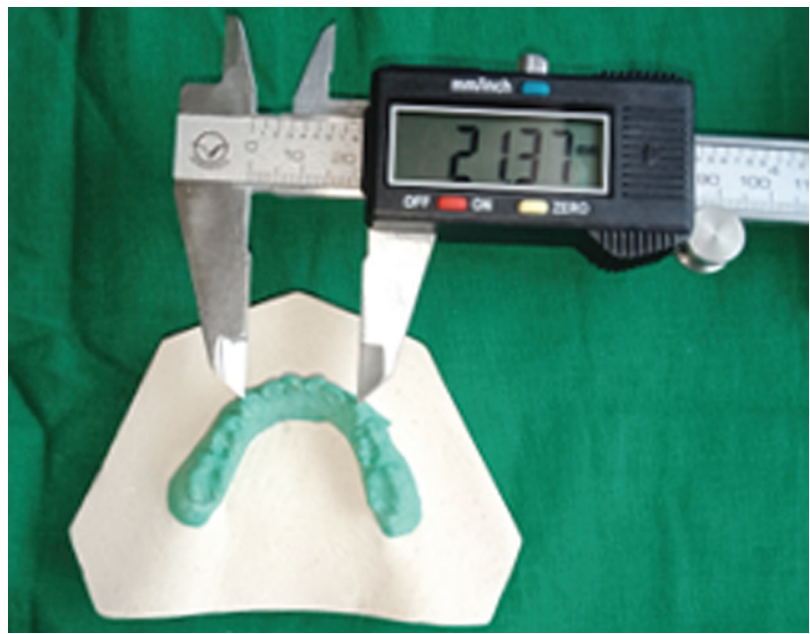

Fig. 5: Measurement of mandibular intercanine distance

$$
\text { Sexual dimorphism }=X m-1 \times 100 / X f
$$

Where $\mathrm{Xm}=$ mean intermolar width of males and $\mathrm{Xf}=$ mean intermolar width of females 
All the measurements were carried out by one researcher, however, the same measurements were repeated by a second researcher on randomly selected casts to test for possible intraobserver and interobserver variations in the tooth measurements.

The data were tabulated and statistically analyzed with SPSS version 21 using the unpaired " $t$ " test. A $p$ value of $<0.05$ was considered to be statistically significant.

\section{Results}

Table 1 represents the tabular presentation of an $\mathrm{MCl}$ between males and females, where a statistically significant difference is present with $p$ value $=0.01$. The $\mathrm{MCl}$ for males is found to be $0.26 \pm 0.058 \mathrm{~mm}$ and for females, it is $0.24 \pm 0.035 \mathrm{~mm}$.

Table 2 represents the tabular of mandibular intercanine width between males and females. The intercanine width in males was found to be $22.48 \pm 3.79 \mathrm{~mm}$ and in females, it was found to be 23.41 $\pm 2.94 \mathrm{~mm}$; however, the difference was not statistically significant.

Table 3 represents the tabular presentation of mandibular intermolar width between males and females. The intermolar width was found to be $35.64 \pm 2.69$ in males and $34.46 \pm 2.01$ in females. There was no statistical significance between the two groups.

The percentage of sexual dimorphism was calculated by using Garn and Lewis ${ }^{6}$ formula and according to the present study, the sexual dimorphism was $3.14 \%$.

\section{Discussion}

Forensic odontology is a branch of science dealing with investigations of age estimation and bite marks. Dental maturity has played an important role in estimating the chronological age of individuals. Forensic odontologist helps in identification of deceased victims by age, sex, and race determination from teeth and skull. ${ }^{7}$

With an increase in the number of natural, as well as man-made calamities such as earthquakes, floods, wars, and riots, the need to correctly identify the remains of dead individuals has increased. Individual identification depends on different parameters such as age, gender, and race. Gender determination is one of the important steps employed in the identification of an individual. If the sex of the individual is evaluated, either male or female and if

Table 1: Mandibular canine index (MCl)

\begin{tabular}{llll}
\hline Parameter & Sex & Mean \pm SD & p value \\
\hline Mean canine index & Male & $0.26 \pm 0.058$ & 0.01 \\
& Female & $0.24 \pm 0.035$ & 0.01 \\
\hline
\end{tabular}

Table 2: Mandibular intercanine width

\begin{tabular}{llll}
\hline Parameter & Sex & Mean $\pm S D$ & pvalue \\
\hline Intercanine width & Male & $22.48 \pm 3.79$ & 0.13 \\
& Female & $23.41 \pm 2.94$ & 0.13 \\
\hline
\end{tabular}

Table 3: Mandibular intermolar width

\begin{tabular}{llll}
\hline Parameter & Sex & Mean \pm SD & p value \\
\hline Intermolar width & Male & $35.64 \pm 2.69$ & 0.24 \\
& Female & $34.46 \pm 2.01$ & 0.24 \\
\hline
\end{tabular}

identified accurately, the total number of missing or lost victims can be confined to just half of the total population of both the sexes. ${ }^{8}$

Sexual dimorphism is a phenotypic differentiation between males and females of the same species. The sex difference is a distinction of biological and/or physiological characteristics associated with either males or females of a species. In 1871, Charles Darwin advanced the theory of sexual selection, which related sexual dimorphism with sexual selection. Externally, the most sexually dimorphic portions of the body are the chest, the lower half of the face, and the area between the waist and knees. ${ }^{6}$

Although the DNA profile gives accurate results yet measurement of linear dimensions such as anthropometric or odontometric parameters can be used for the determination of sex in a large population because they are simple, reliable, inexpensive, and easy to measure. The fact that most teeth complete development before skeletal maturation makes dentition a valuable sex indicator, particularly in young individuals. ${ }^{4}$ In addition, the degree to which they provide resistance to damage in terms of bacterial decomposition, fire, and fracture, makes them valuable for forensic investigation and research. ${ }^{9,10}$ The teeth being one of the strongest human tissues are known to resist various antemortem and postmortem insults and are one of the most commonly recovered remains. They exhibit the least turnover of natural structure and are readily accessible for examination. In major disasters where postcranial bones are fragmented, measurement of teeth dimension provides evidence of sexual identification due to dimorphism. ${ }^{11}$

Because there are differences in odontometric features in specific populations, even within the same population in the historical and evolutional context, it is necessary to determine specific population values to make identification possible based on dental measurements. ${ }^{12}$ The present study established the impact of sex factor on the morphometry of primary mandibular canines and second molars in a Davangere population.

Canines differ from other teeth with respect to survival and sex dichotomy. The mandibular canines are not only exposed to less plaque, calculus, abrasion from brushing, or heavy occlusal loading than other teeth, they are also less severely affected by periodontal disease and so, usually are the last teeth to be extracted with respect to age. ${ }^{13}$ Mesiodistal width of canine, ${ }^{14,15}$ intercanine width, ${ }^{8}$ and $\mathrm{MCl}^{16}$ have been used to determine gender in the past and are supported by many researchers. However, recent research by Acharya et al. ${ }^{17,18}$ and Boaz and Gupta $^{19}$ in adults have found that these measurements do not reflect the gender difference accurately. Furthermore, these measurements are not useful in individuals with missing canines. In such cases, the width of molars or intermolar arch width may be used in gender determination. ${ }^{20}$

The measurements of linear dimensions which include the MD width of canine teeth have the advantage of being able to use a large sample of the population because it is simple, inexpensive, and easy to perform. Kaushal et al. ${ }^{21}$ found that adult males exhibit larger MD width than females. It is consistent with $\mathrm{Nair}^{22}$ who conducted a study on South Indian males and females in the age group of 16-28 years and found that the canines in both jaws exhibited a significant sexual difference. Despite the tooth size variability factors, the studies conducted by Ghose and Baghdady ${ }^{23}$ on the Iraqi population, Lysell and Myrberg ${ }^{24}$ on Swedish population, and by Bishara et al. ${ }^{25}$ on populations of Egypt, Mexico, and lowa showed consistent findings that the MD width of 
the mandibular canines is more in the adult males than the females and the difference is statistically significant.

Studies performed on the lower canines using the ratio between the maximum crown width and canine arch width, resulting in an $\mathrm{MCl}$, have shown an ability to determine gender when performed on 384 females and 382 males of the South Indian population in the age group of 15-21 years with an accuracy of $84.3 \%$ in males and $87.5 \%$ in females by comparing the observed $\mathrm{MCl}$ with a standard $\mathrm{MCl}$ value. In a similar study by Muller et al., ${ }^{26}$ the population involved the students enrolled in the University of Nice-Sophia Antipolis 210 girls and 214 boys were randomly sampled. The results were found to be statistically significant. In the present study, both these parameters as measured in males and females were compared and the difference was found to be statistically significant.

Although sex differences in intermolar width have been previously reported in adults, this is one of the first studies to show statistically significant sex differences in children. ${ }^{27-29}$ Small sex differences have been reported at younger ages, but the differences were not statistically significant. ${ }^{30,31}$ Arch width increases have been previously reported between 7 years and 17 years of age. ${ }^{32-34}$ Importantly, approximately $73 \%$ of the total maxillary intercanine width increases, and $84 \%$ of the total maxillary intermolar width increases occurred between 6 years and 9 years of age. The fact that most increases occurred early can be supported by previous longitudinal studies. ${ }^{27,32-34}$ The increases, particularly the intermolar width increases, were more likely related to growth than to dental maturation. These findings are clinically important because prolonged treatments of children in this age range with lingual arches, Hawleys, Schwarz plates, and transpalatal arches to maintain or gain arch length could be restricting normal transverse development. ${ }^{35}$

In our study, $\mathrm{MCl}$, intercanine width, and intermolar arch width were used to determine gender and the results were compared to assess a better method to determine gender correctly. The present study establishes the existence of a definite statistically significant sexual dimorphism in mandibular canines. It is consistent with Hashim and Murshid ${ }^{36}$ who conducted a study on Saudi males and females in the age group of 13-20 years and found that only the canines in both jaws exhibited a significant sexual difference while the other teeth did not. Similar findings were given by Lew and Keng $^{37}$ in their study on ethnic Chinese populations with normal occlusions. Kumar et al. ${ }^{38}$ have demonstrated that intercanine distance and $\mathrm{MCl}$ are useful parameters in differentiating the sexes.

There was no significant difference between the mean mandibular intercanine widths between males and females. This observation is in agreement with other studies done by Bishara et al. ${ }^{39}$ and Rai et al. ${ }^{40}$ Since crowding tends to decrease the anterior dental arch width and crowding is more common in the mandibular anterior, this could be the reason for the above-mentioned finding. However, this observation is in disagreement with a study done by Hussein et al. ${ }^{41}$ as they found the mandibular intercanine width to be greater in males.

In our study, no statistical significant difference was seen in intermolar width between boys and girls, this was, in contrast, to study done by Hartomo et al., ${ }^{42}$ who conducted a study on 150 male and 150 female mandibular models, age 16-60 years of Indonesian citizens and found the results that both mandibular intercanine and intermolar width values were higher in male significantly than in the female. A study done by Gupta and Daniel ${ }^{43}$ stated that male mandibular intermolar distance the wider than female. Astete et al. ${ }^{44}$ concluded in their study that the mean values for mandibular and maxillary intercanine and intermolar distances for females were less than for males.

However, more studies have to be carried out with more samples to support and standardize definite values for sex identification with reference to MD width of canine, intercanine distance, and intermolar arch width in both males and females.

\section{Conclusion}

Intermolar distance can be used as an alternative tool for sex determination as an inexpensive and alternative method.

\section{Clinical Significance}

First study in itself to determine gender in the pediatric population in the city of Davangere, India.

\section{References}

1. Rajendran R, Sivapathasundharam B, ed. Shafer's textbook of oral pathology. 7th ed., New Delhi: Elsevier; 2012. p. 879.

2. Deebaei A, Moghaddam HF, Delkhosh P. The statistical analysis of application of teeth in forensic odontology center. Pak J Med Sci 2008:24:48-51.

3. Gupta B, Gupta M. Sex identification in forensic odontology-a review of various methodology. Int J Forensic Odontol 2016;1(1):9-13. DOI: 10.4103/2542-5013.185693.

4. Lund $\mathrm{H}$, Mörnstad $\mathrm{H}$. Gender determination by odontometrics in a Swedish population. J Forensic Odontostomatol 1999;17:30-34.

5. Manchanda AS, Narang RS, Kahlon SS, et al. Diagonal tooth measurements in sex assessment: a study on North Indian population. J Forensic Den Sci 2015;7(2):0975-1475.

6. Syed MA, Selarka B, Tarsariya V. Sexual dimorphism in permanent maxillary and mandibular canines and intermolar arch width: endemic study. J Indian Acad Oral Med Radiol 2015;27(3):405-411. DOI: 10.4103/0972-1363.170473

7. Amina M, Bano K, Babu Y. Comparison of intercanine and intermolar width of the maxilla as an aid in gender determination: a preliminary study. Drug Invention Today 2018;10(3).

8. Sherfudhin $\mathrm{H}$, Abdullah MA, Khan N. A cross-sectional study of canine dimorphism in establishing sex identity: comparison of two statistical methods. J Oral Rehabil 1996;23(9):627-631. DOI: 10.1046/j.13652842.1996.00406.x.

9. Acharya $A B$, Mainali $S$. Univariate sex dimorphism in the Nepalese dentition and the use of discriminant functions in gender assessment. Forensic Sci Int 2007;173(1):47-56. DOI: 10.1016/j.forsciint.2007.01.024.

10. Vahanwahal SP, Parekh DK. Study of lip prints as an aid to forensic methodology. J Ind Dent Assoc 2000;17(1):12-18.

11. Vodanović M, Demo Ž, Njemirovskij V, et al. Odontometrics: a useful method for sex determination in an archaeological skeletal population. J Archaeol Sci 2007;34(6):905-913. DOI: 10.1016/j. jas.2006.09.004

12. Işcan MY, Kedici PS. Sexual variation in bucco-lingual dimensions in Turkish dentition. Forensic Sci Int 2003;137(2-3):160-164. DOI: 10.1016/ S0379-0738(03)00349-9.

13. Anderson DL, Thompson GW. Interrelationships and sex differences of dental and skeletal measurements. J Dent Res 1973;52(3):431-438. DOI: 10.1177/00220345730520030701.

14. Kapila R, Nagesh KS, lyengar AR, et al. Sexual dimorphism in human mandibular canines: a radiomorphometric study in South Indian population. J Dent Res Dent Clin Dent Prospects 2011;5:51-54.

15. Gorea RK, Sharma M. Odontometric study of canines of Indian population for sex determination. J Indo Pac Acad Forensic Odontol 2010;1:34-37. 
16. Reddy VM, Saxena S, Bansal P. Mandibular canine index as a sex determinant: a study on population of western Uttar Pradesh. J Oral Maxillofac Pathol 2008;12(2):56-59. DOI: 10.4103/0973-029X.44577.

17. Acharya $A B$, Mainali $S$. Limitations of the mandibular canine index in sex assessment. J Forensic Leg Med 2009;16(2):67-69. DOI: 10.1016/j. jflm.2008.08.005.

18. Acharya AB, Angadi PV, Prabhu S, et al. Validity of the mandibular canine index $(\mathrm{MCl})$ in sex prediction: reassessment in an Indian sample. Forensic Sci Int 2011;204(1-3):207. DOI: 10.1016/j.forsciint.2010. 08.002 .

19. Boaz K, Gupta C. Dimorphism in human maxillary and mandibular canines in establishment of gender. J Forensic Dent Sci 2009;1(1):4244. DOI: $10.4103 / 0974-2948.50889$.

20. Sonika V, Harshaminder K, Madhushankari GS, et al. Sexual dimorphism in the permanent maxillary first molar: a study of the Haryana population (India). J Forensic Odontostomatol 2011;29: 37-43.

21. Kaushal S, Chhabra U, Aggarwal B, et al. Significance of mesiodistal diameters of the mandibular permanent canine in sexual dimorphism. J Punjab Acad Forensic Med Toxicol 2008;8:22-25.

22. Nair P, Rao BB, Annigeri RG. A study of tooth size, symmetry and sexual dimorphism. J Forensic Med Toxicol 1999;16:10-13.

23. Ghose LJ, Baghdady VS. Analysis of the Iraqi dentition. Mesiodistal crown diameters of permanent teeth. J Dent Res 1979;58(3):10471054. DOI: $10.1177 / 00220345790580030301$

24. Lysell L, Myrberg N. Mesiodistal tooth size in the deciduous and permanent dentitions. Eur J Orthod 1982;4(2):113-122. DOI: 10.1093/ ejo/4.2.113.

25. Bishara SE, Jakobsen JR, Abdallah EM, et al. Comparisons of mesiodistal and buccolingual crown dimensions of the permanent teeth in three populations from Egypt, Mexico, and the United States. Am J Orthod Dentofacial Orthop 1989;96(5):416-422. DOI: 10.1016/0889-5406(89)90326-0.

26. Muller M, Lupi-Pegurier L, Quatrehomme G, et al. Odontometrical method useful in determining gender and dental alignment. Forensic Sci Int 2001;121(3):194-197. DOI: 10.1016/S0379-0738(01) 00399-1.

27. Knott VB. Longitudinal study of dental arch widths at four stages of dentition. Angle Orthod 1972;42:387-395.

28. Sillman JM. Dimensional changes of the dental arches: longitudinal study from birth to 25 years. Am J Orthod 1964;50(11):824-842. DOI: 10.1016/0002-9416(64)90040-5.

29. Cassidy KM, Harris EF, Tolley EA, et al. Genetic influence on dental arch form in orthodontic patients. Angle Orthod 1998;68:445-454.
30. Lux CJ, Conradt C, Burden D, et al. Transverse development of the craniofacial skeleton and dentition between 7 and 15 years of age-a longitudinal postero-anterior cephalometric study. Eur J Orthod 2004;26(1):31-42. DOI: 10.1093/ejo/26.1.31.

31. Lux CJ, Conradt C, Burden D, et al. Dental arch width and mandibularmaxillary base widths in Class II malocclusion between early mixed and permanent dentitions. Angle Orthod 2003;73:674-685.

32. Moorrees CFA, Reed RB. Changes in dental arch dimensions expressed on the basis of tooth eruption as a measure of biologic age. J Dent Res 1965;44(1):129-141. DOI: 10.1177/00220345650440010601.

33. Bishara SE, Jakobsen JR, Treder J, et al. Arch width changes from 6 weeks to 45 years of age. Am J Orthod Dentofacial Orthop 1997;111(4):401-409. DOI: 10.1016/S0889-5406(97)80022-4.

34. Moyers RE, Van der Linden FPGM, Riolo ML, et al. Standards of human occlusal development. Monograph 5. Craniofacial growth series. Ann Arbor: Center for Human Growth and Development; University of Michigan; 1976.

35. Alvaran N, Roldan SI, Buschang PH. Maxillary and mandibular arch widths of Colombians. Am J Orthod Dentofacial Orthop 2009;135(5):649-656. DOI: 10.1016/j.ajodo.2007.05.023.

36. Hashim HA, Murshid ZA. Mesio-distal tooth width - A comparison between Saudi males and females. Egypt Dent J 1993;39(1):343-346.

37. Lew KK, Keng SB. Anterior crown dimensions and relationship in an ethnic Chinese population with normal occlusions. Aust Orthod J 1991;12(2):105-109.

38. Kumar N, Rao G, Rao NN, et al. Mandibular canine index - A clue for establishing sex identity. Forensic Sci Int 1989;42(1):249-254.

39. Bishara SE, Treder JE, Damon P, et al. Changes in the dental arches and dentition between 25 and 45 years of age. Angle Orthod 1996;66(6):417-422.

40. Rai B, Kaur J, Dhattarwal SK, et al. Changing maxillary and mandibular inter-canine and inter-molar distance between 8 to 20 years: male and female. Internet J Forensic Sci 2008;3(1):4.

41. Hussein KW, Rajion ZA, Hassan R, et al. Variations in tooth size and arch dimensions in Malay school children. Aust Orthod J 2009;25:163-168.

42. Hartomo BT, Adrianto AWD, Anas AN, et al., The use of human intercanine and intermolar for determining sex on natural disaster. 2019.

43. Gupta J, Daniel MJ. Crown size and arch width dimension as an indicator in gender determination for a Puducherry population. J Forensic Dent Sci 2016;8(3):120-125. DOI: 10.4103/0975-1475.195105.

44. Astete JC, San Pedro VJ, Suazo Gl. Sexual dimorphism in the tooth dimensions of Spanish and Chilean peoples. Int J Odontostomat 2009:3:47-50. 